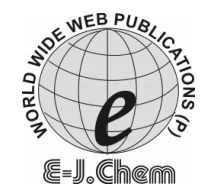

http://www.e-journals.net
ISSN: 0973-4945; CODEN ECJHAO

E-Journal of Chemistry

Vol. 5, No.3, pp. 634-640, July 2008

\title{
LC-MS-MS Method for Determination of Metolazone in Human Plasma
}

\author{
SHIKHA M. N. ROY*, KIRAN V. MANGAONKAR, \\ SANTOSH. M. YETAL and SANTOSH. S. JOSHI \\ Department of Chemistry, Ramnarain Ruia College, \\ Matunga, Mumbai - 400 019, India. \\ santosh_yetal@yahoo.com
}

Received 7 August 2007; Revised 30 October 2007; Accepted 20 December 2007

\begin{abstract}
A rapid, sensitive and specific method for quantification of metolazone in human plasma using metaxalone as internal standard is described. Sample preparation involved a simple liquid-liquid extraction procedure. The extract was analyzed by high performance liquid chromatography coupled to electrospray tandem mass spectrometry (LC-MSMS). Chromatography was performed isocratically on a $5 \mu \mathrm{m} \mathrm{C}_{18}$ analytical column $(50 \mathrm{~mm} \times 4.6 \mathrm{~mm}$ i.d.) with buffer-acetonitrile $20: 80(\mathrm{v} / \mathrm{v})$ as mobile phase. The response to metolazone was a linear function of concentration over the range 1.00 to $2000.00 \mathrm{ng} \mathrm{mL}^{-1}$. The lower limit of quantification in plasma was $1.0 \mathrm{ng} \mathrm{mL}^{-1}$. The method was successfully applied in a bioequivalence study of a metolazone formulation after administration as a single oral dose.
\end{abstract}

Keywords: Metolazone, Human plasma, LC-MS-MS.

\section{Introduction}

Metolazone has the molecular formula $\mathrm{C}_{16} \mathrm{H}_{16} \mathrm{ClN}_{3} \mathrm{O}_{3} \mathrm{~S}$ and the chemical name 7-chloro-1, 2,3,4-tetrahydro-2-methyl-3-(2-methylphenyl)-4-oxo-6-quinazolinesulfonamide with molecular weight ${ }^{7}$ of 365.83 . Metolazone is a quinazoline diuretic with properties generally similar to the thiazide diuretics. The actions of metolazone result from interference with the renal tubular mechanism of electrolyte reabsorption. Metolazone acts primarily to inhibit sodium potassium excretion. Metolazone does not inhibit carbonic anhydrase. A proximal action of metolazone has been shown in humans by increased excretion of phosphate and magnesium ions and by a markedly increased fractional excretion of sodium in patients with severely compromised glomerular filtration ${ }^{6-16}$. Previous work shows metazalone has been determined in biological fluids such as human plasma, blood and urine with high pressure liquid chromatography with fluorescence detector and coupled mass detector ${ }^{1-5}$. The objective of this study was to develop a simple, inexpensive, sensitive, rapid, and accurate method for analysis of metolazone in human plasma with reliable reproducibility suitable for pharmacokinetic studies. 


\section{Experimental}

\section{Chemicals and reagents}

Working standard of metolazone was obtained from Centaur Chemical Pvt. Ltd, Mumbai400055, India. Working standard of metaxalone was obtained from Lannett company, Inc.9000 state Rd., Philadelphia. Methanol and acetonitrile of HPLC grade were from J.T. Baker. Ammonium acetate and formic acid of HPLC grade were from BDH Laboratory Reagents, England. HPLC-grade water was from Merck.

\section{Instrumentation and chromatographic conditions}

The HPLC system (Shimadzu LC-20AD) consisted of a binary pump and an autosampler (SIL-HTc). Detection was performed with an Applied Biosystems Sciex (API 2000) mass spectrometer with atmospheric ion spray for ion production, which was controlled by Analyst 1.4 software. Chromatography was performed isocratically on a $50 \mathrm{~mm} \times 4.6 \mathrm{~mm}$ i.d., $5 \mu \mathrm{m}$ particle, thermo hypurity $\mathrm{C}_{18}$ analytical column. The mobile phase was buffer-acetonitrile 20:80 (v/v) at a flow rate of $0.4 \mathrm{~mL} \mathrm{~min}^{-1}$. Buffer was $2 \mathrm{mM}$ ammonium acetate, $\mathrm{pH}$ adjusted to 3.0 with formic acid. Chromatography was performed at ambient temperature. The ionspray potential was set at $5.5 \mathrm{kV}$ and the source temperature was $400^{\circ} \mathrm{C}$. The collision activation dissociation (CAD) gas setting at 4.0; nitrogen was used as collision gas. The instrument was set up in multiple reaction monitoring (MRM) mode; the transition $\mathrm{m} / \mathrm{z}$ $366.1 \rightarrow 259.0$ was monitored for metolazone and the transition $\mathrm{m} / \mathrm{z} 222.2 \rightarrow 161.1$ for metaxalone. Figure 1 and Figure 2 shows MS-MS scan for metolazone and metaxalone.

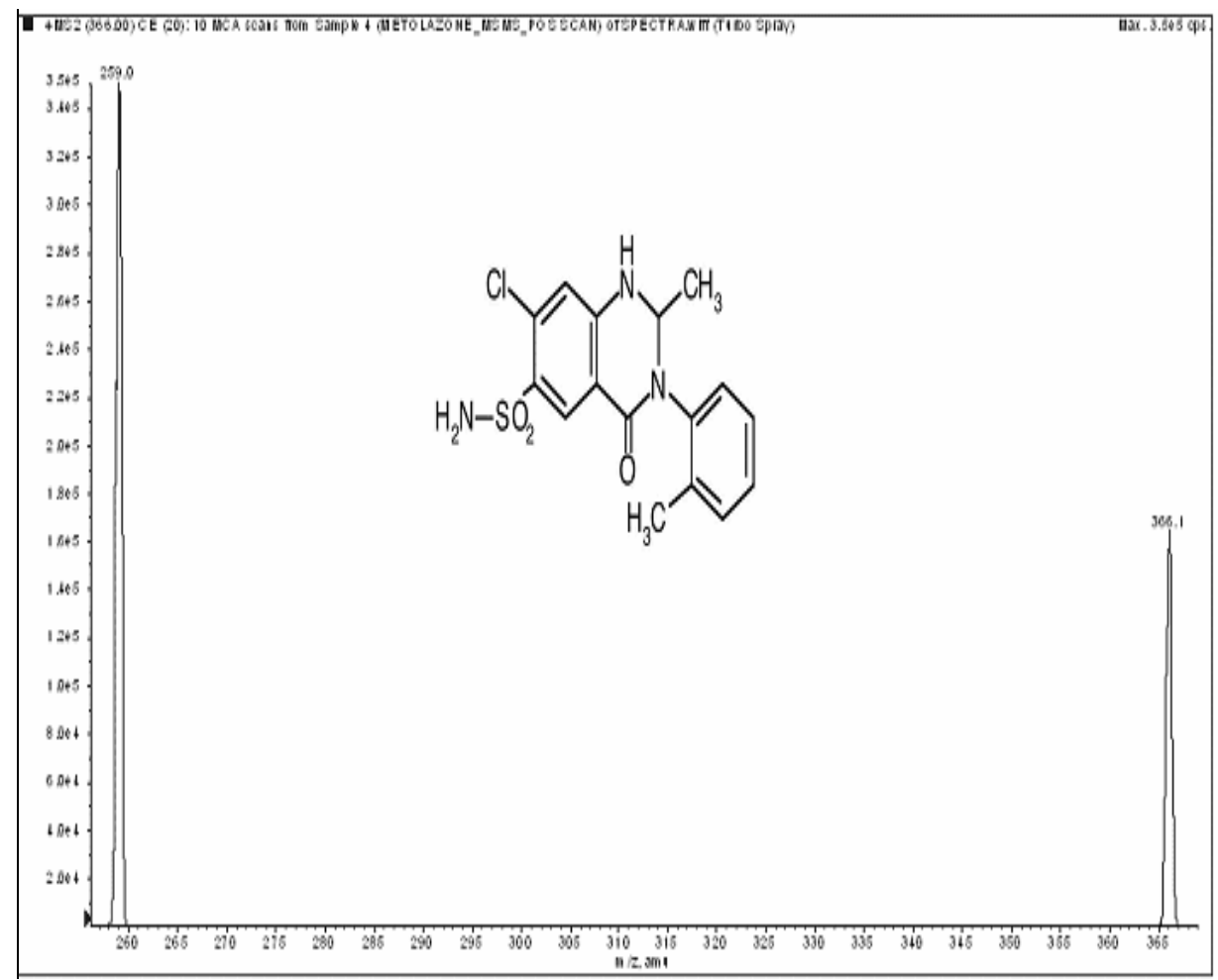

Figure 1. Metolazone MS-MS scan (366.1> 259.0). 


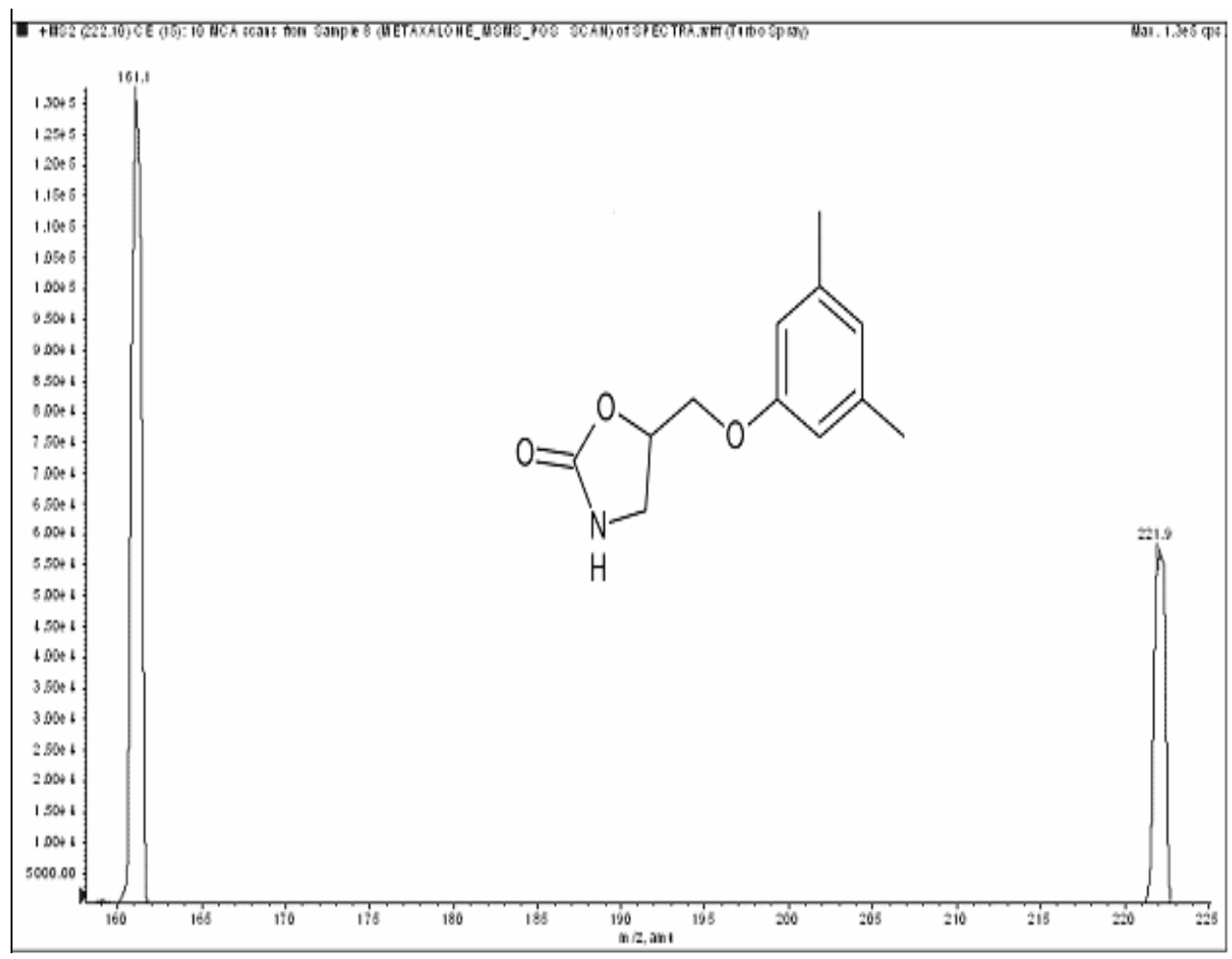

Figure 2. Metaxalone msms scan $(222.2>161.1)$

Preparation of stock solution and calibration and quality control samples

A stock solution of metolazone $\left(1000.00 \mu \mathrm{g} \mathrm{mL}^{-1}\right)$ and metaxalone $\left(1000.00 \mu \mathrm{g} \mathrm{mL}^{-1}\right)$ were prepared in methanol. A series of working standard of metolazone containing 20, 50, 500, $100010000,20000,30000$ and $40000 \mathrm{ng} \mathrm{mL}^{-1}$ was prepared by diluting the stock solution with diluent methanol-water 60:40 (v/v). Working internal standard solution $\left(10.00 \mu \mathrm{g} \mathrm{mL}^{-1}\right)$ was prepared in methanol and water in the ratio 60:40 (v/v). Low, medium and high concentration quality control solutions $\left(60.00,4000.00\right.$ and $35000.00 \mathrm{ngmL}^{-1}$, respectively) were prepared in diluents methanol and water in the ratio $60: 40(\mathrm{v} / \mathrm{v})$. Calibration plot standards were prepared by spiking blank plasma with metolazone at concentration of 1.00, 2.50, 25.00, 50.00, 500.00, $1000.00,1500.00$ and $2000.00 \mathrm{ng} \mathrm{mL}^{-1}$. Quality control samples were prepared by spiking blank plasma with 3.00, 200.00 and $1750.00 \mathrm{ng} \mathrm{mL}^{-1}$ metolazone. Stock solutions were stored at $4-8^{\circ} \mathrm{C}$ and used within 33 days of preparation

\section{Sample preparation}

To $2.0 \mathrm{~mL}$ polypropylene centrifuge tube, $500 \mu \mathrm{L}$ of plasma sample was spiked with $50.00 \mu \mathrm{L}$ of internal standard $\left(10 \mu \mathrm{g} \mathrm{mL}^{-1}\right)$ solution, $25 \mu \mathrm{L}$ diluent (or Metolazone working calibration standard solution or quality-control solution) and $1.5 \mathrm{~mL}$ methyl tert-butyl ether were added. Samples were vortexed for 10.0 minutes followed by centrifugation at $15000 \mathrm{x} \mathrm{g}$ for 10 minutes. The supernatant layer was separated and evaporated to dryness under a stream of nitrogen at $50^{\circ} \mathrm{C}$. The dry residue was dissolved with $250 \mu \mathrm{L}$ of mobile phase, vortexes for 1.0 minute and $10 \mu \mathrm{L}$ of the sample was injected 


\section{Validation procedures}

The method was validated in accordance with current acceptance criteria. The specificity of the analytical method was investigated by extraction and analysis of blank plasma samples from six different sources to assess potential interference from endogenous substances. The apparent response at the retention times of metolazone and metaxalone was compared with that at the lower limit of quantification $\left(1.0 \mathrm{ng} \mathrm{mL}^{-1}\right)$. Representative chromatograms illustrating the specificity of the method are shown in Figure 3 and 4. The acceptance criterion for metolazone was that the mean interference from the six individual sources should be $\leq 20 \%$ of the signal at the LLOQ and that the mean interference for metaxalone (internal standard) from the six individual sources should be $\leq 5 \%$ of the signal at working concentration

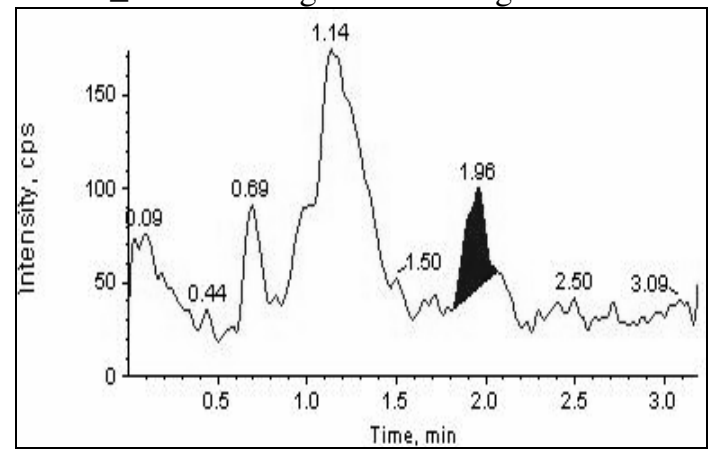

Figure 3. Representative chromatogram plasma blank for Metolazone

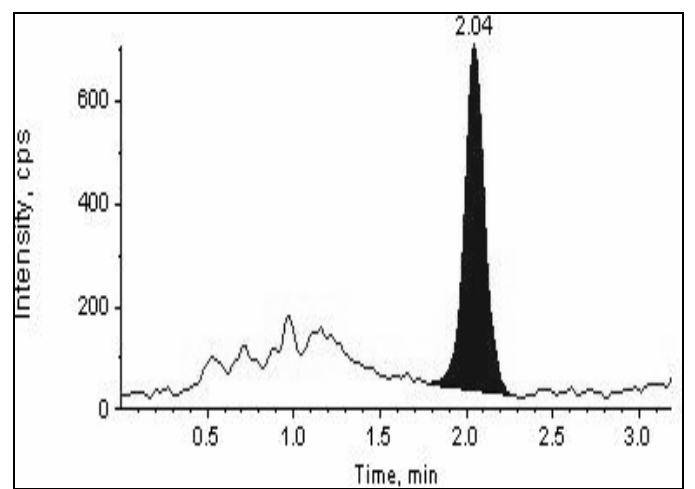

Figure 4. Representative chromatogram plasma spiked with metolazone at the lower limit of quantification

The calibration equation was determined by least-squares linear regression (weighting $1 / X^{2}$ ) over the range 1.0 to $2000.0 \mathrm{ng} \mathrm{mL}^{-1}$ in plasma. The precision and accuracy of the methods were determined at the three QC sample levels for six replicates together with calibration samples from different validation batches. The basic fundamental properties studied during method validation were the stability of stock solution stored at $4-8^{\circ} \mathrm{C}$ for one month, freeze thaw stability through three cycles, short term stability, an autosampler stability and long term stability. For freeze thaw stability, QC plasma samples were subjected to three cycles from $-20^{\circ} \mathrm{C}$ to room temperature. Short term bench top stability was determined by placing samples on the bench top at ambient temperature for $24 \mathrm{~h}$. An autosampler stability was assessed by placing processed QC samples in an autosampler at 
$10^{\circ} \mathrm{C}$ for $24 \mathrm{~h}$ and long term stability was evaluated by freezing QC samples at $-20^{\circ} \mathrm{C}$ for a month. Recovery was assessed by comparing the peak areas of neat analyte standards with those for spiked standards at three concentrations before and after extraction ${ }^{17}$.

\section{Pharmacokinetic application}

The method was used to determine pharmacokinetic data for metolazone in human volunteers.

\section{Results and Discussion}

The assay was found to be linear for metolazone concentrations in the range 1.0 to $2000.00 \mathrm{ng} \mathrm{mL}^{-1},(\mathrm{r}=0.9998)$.

Table 1. correlation coefficient (r)

\begin{tabular}{cccc}
\hline Calibration curve & Slope & Intercept & Regression \\
\hline 1 & 0.007220 & 0.000789 & 0.9973 \\
2 & 0.007310 & 0.00284 & 0.9990 \\
3 & 0.007570 & 0.00384 & 0.9985 \\
4 & 0.007110 & 0.00138 & 0.9970 \\
Mean & 0.007303 & 0.002212 & 0.9980 \\
\hline
\end{tabular}

$n=4$

Precision and accuracy were studied satisfactory at three QC concentrations. The intraday precision and accuracy of the method at QC levels $\left(3.0 \mathrm{ng} \mathrm{mL}^{-1}, 200.0 \mathrm{ng} \mathrm{mL}^{-1}\right.$, and $\left.1750.0 \mathrm{ng} \mathrm{mL}^{-1}, n=6\right)$ were $5.43,5.63$ and $4.27 \%$ and $106.10,104.59$ and $102.07 \%$, respectively. The inter-day precision and accuracy of the method at QC levels $(n=6)$ were 5.82, 5.27 and $5.13 \%$ and $106.58,103.97$ and $100.55 \%$ respectively. The results obtained from measurement of linearity, precision and accuracy are listed in Tables 2 and 3.

Table 2. Concentrations of metolazone in calibration standards prepared in human plasma.

\begin{tabular}{cccc}
\hline & Nominal $^{*}$ & Mean* & CV, \% \\
\hline Level 1 & 1.000 & 0.972 & 0.81 \\
Level 2 & 2.500 & 2.667 & 1.78 \\
Level 3 & 25.000 & 26.366 & 6.10 \\
Level 4 & 50.000 & 47.465 & 1.09 \\
Level 5 & 500.000 & 482.972 & 1.00 \\
Level 6 & 1000.000 & 981.670 & 8.19 \\
Level 7 & 1500.000 & 1491.657 & 4.08 \\
Level 8 & 2000.000 & 2030.249 & 2.37 \\
\hline
\end{tabular}

*ng $m L^{-1} ; n=4$

Table 3. Data of inter day precision and accuracy.

\begin{tabular}{cccccccc}
\hline & & \multicolumn{3}{c}{ Inter Day } & \multicolumn{3}{c}{ Intra Day } \\
\hline Drug & Nominal* $^{*}$ & Mean* & Accuracy,\% & CV, \% & Mean* & Accuracy,\% & CV, \% \\
LQC, $n=6$ & 3.000 & 3.197 & 106.58 & 5.82 & 3.183 & 106.10 & 5.43 \\
MQC, $\mathrm{n}=6$ & 200.000 & 207.933 & 103.97 & 5.27 & 209.176 & 104.59 & 5.63 \\
HQC, $\mathrm{n}=6$ & 1750.000 & 1759.618 & 100.55 & 5.13 & 1786.211 & 102.07 & 4.27 \\
\hline
\end{tabular}

*ng $m L^{-1} ; n=3$

The extraction recovery of the method at QC levels $(n=6)$ was 62.23, 67.40 and $78.58 \%$, respectively. Absolute mean recovery of metolazone and the internal standard (metaxalone) were $69.41 \& 79.46 \%$ respectively. Stock solution stored at $4-8^{\circ} \mathrm{C}$ was found to be stable for 33 days. When drug stability at the LQC and HQC concentrations was measured after three freeze thaw cycles, the differences from freshly prepared samples 1.28 
and $3.54 \%$ respectively were low. When bench top stability at the LQC and HQC concentrations for $24 \mathrm{~h}$ was measured the differences from freshly prepared QC samples were -4.33 and $-1.07 \%$ respectively. When an autosampler stability at the LQC and HQC concentrations for $24 \mathrm{~h}$ was measured, the differences from freshly prepared samples were approximately 1.52 and $0.77 \%$ respectively. When drug stability in the matrix at $-20^{\circ} \mathrm{C}$ for 31 days was measured at the LQC and HQC concentrations difference from freshly prepared samples were 4.78 and $-2.57 \%$ respectively.

Table 4. Concentrations of metolazone in stability sample prepared in human plasma

\begin{tabular}{cccc}
\hline Stability & Nominal $^{*}$ & \% Difference & CV, \% \\
\hline Bench top & 3.000 & -4.33 & 9.64 \\
& 1750.000 & -1.07 & 5.32 \\
Freeze thaw & 3.000 & 1.28 & 3.54 \\
& 1750.000 & 3.54 & 5.32 \\
Auto sampler & 3.000 & 1.52 & 2.32 \\
& 1750.000 & 0.77 & 5.32 \\
Drug stability in matrix & 3.000 & 4.78 & 12.23 \\
& 1750.000 & -2.57 & 9.99 \\
\hline
\end{tabular}

$$
\text { *ng } m L^{-1} ; n=6
$$

\section{Pharmacokinetic application}

After oral administration to volunteers, the observed peak plasma concentration $\left(C_{\max }\right)$ was $49.00 \mathrm{ng} \mathrm{mL}^{-1}$ for test and $49.66 \mathrm{ng} \mathrm{mL}^{-1}$ for reference. The time $\left(T_{\max }\right)$ taken to achieve peak plasma concentration were 2.83 hours for test and 2.75 hours for reference. In addition, the calculated $90 \%$ confidence interval (CI) for mean $C_{\max }, A U C_{\text {last }}$, and $\mathrm{AUC}_{0-\infty}$ individual ratios were within the $80-125 \%$ interval stipulated by the US Food and Drug Administration. ${ }^{18}$

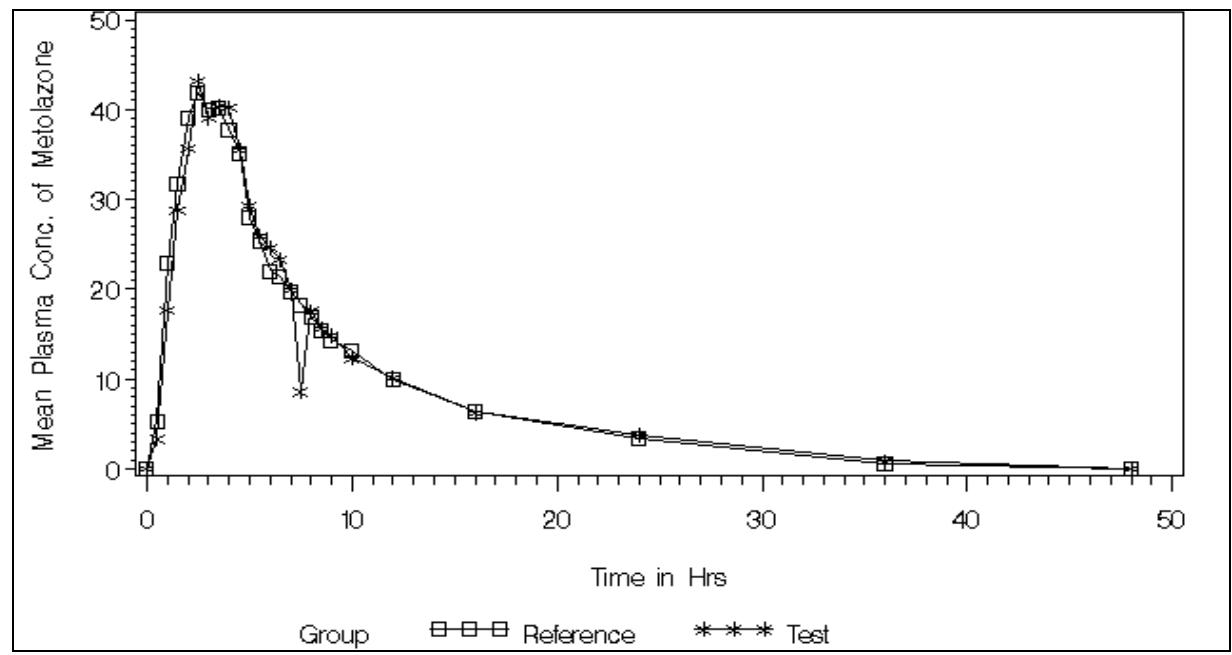

Figure 5. Mean plasma concentration -time profile of metolazone after a single oral dose of metolazone (USP 5mg) tablet to healthy male volunteers.

LC-MS-MS analysis with a reversed-phase column and low aqueous high organic mobile phases was found to be ideal for the analysis. Increasing the organic content of the mobile phase resulted in improved sensitivity by enhancement of the ionization yield. ${ }^{19-21}$. Use of methanol as 
the organic component of the mobile phase did not result in adequate sensitivity and selectivity, owing to bad peak shape and increased interference from the plasma. Acetonitrile as organic component and $\mathrm{pH}$ of buffer, resulted in better sensitivity, but variation of the amount of acetonitrile in the mobile phase effected the run time. The mobile phase was optimized to provide sufficient selectivity in a short separation time. Analyte and internal standard responded best to positive ionization using atmospheric turbo ion spray for ion production. In order to get higher response hypersil hypurity $(4.6 \times 50 \mathrm{~mm}), 5 \mu$, Column was used. The $\mathrm{pH}$ of mobile phase adjusted to 3.0 with formic acid. The assay was found to be linear in the conc. range 1.000 to $2000.000 \mathrm{ng} \mathrm{mL}^{-1}$ for metolazone. Precision and accuracy were satisfactory at the three conc. studied. Absolute mean \% recovery of the metolazone and metaxalone is $69.41 \& 79.46 \%$ respectively. Recovery of an analyte and internal standard is consistent, precise and reproducible Stability of analyte and internal standard in methanol stock sol. was verified on storage for 33 days at $2-8^{\circ} \mathrm{C}$. The proposed method proved accurate and selective and met the standards for bioanalytical Method Validation accepted by the FDA ${ }^{17}$

\section{Conclusion}

Rapid and sensitive LC-MS-MS method is reported for the determination of metolazone in human plasma. The Assay was successfully applied to determine concentration of the drug in a bioequivalence study of metolazone. The method developed allows high samples through put due short run time and relatively simple sample preparation procedure. Advantages of wide Linearity range $1.0 \mathrm{ng} \mathrm{mL}^{-1}$ to $2000 \mathrm{ng} \mathrm{mL}^{-1}$ of the method is applicable for various dose of metolazone.

\section{References}

1. Guangli W, Shuhua X and Changxiao L, J Chromatogr., B, 2007, 845(1), 169-173.

2. Kim Y, Kim S and Lee W, Rapid Comm. Mass Spectrom., 2004, 18(8), 917-921.

3. Don Farthing, Domenic A. Sica, Itaf Fakhry and Todd W B Gehr, J Chromatogr., B, 1994, 653(2), 171-176.

4. Don Farthing, Itaf Farthing, Todd W B Gehr and Domenic A, J Chromatogr., B, 1990, 534, 228-232.

5. Brodie R, Chasseaud L F and Walmsley L M, J Chromatogr., B, 1981, 226(2), 526-532.

6. Vose C W, Murihead D C, Evans G L, Stevens P M and Burford S R, J Chromatogr., $B, 1981,222(2), 311-315$.

7. Belair E J, Res Commun Chem Pathol Pharmacol, 1971, 2, 98-177.

8. Cangiano J L, Campos J A and Trevino A, Curr. Ther. Res., 1974, 16, 778-785.

9. Fernadez P C and Puschett J B, Am. J. Physiol., 1973, 225, 954-961.

10. Materson B J, Modern Medicine, 1988, 56,47-52.

11. Miller R P, Woodworth J R and Graves D A, Curr. Ther. Res., 1988,43(6), 1133-1142.

12. Moser M., Clin. Ther., 1986, 8(5),554-562.

13. Puschett J B, Modern Medicine, 1988, 56, 53-61.

14. Schoenberger J A., Health Sci. Rev., 1982, 1,1-53.

15. Shetty BV, Campanella LA and Thomas TL, J Med. Chem., 1970,13,886-895.

16. Webster J, Mechanism and clinicalimplications, Drugs, 1985,30,32-41.

17 Guidance for Industry: Bioanalytical Method Validation. U.S. Department of Health and Human Services. FDA. CDER. CVM. May 2001.

18 U. S. Food and Drug Administration. Guidance for Industry: Statistical Approaches to Establishing Bioequivalence, January 2001.

19 Radhakrishna T, Sreenivas R D and Omreddy G, J Pharm Biomed Anal, 2002, 29(4), 593.

20 Nemutlu E and Kir S J, Pharm. Biomed. Anal., 2003, 31(2), 393-400.

21 Fernandez H, Ruperez F J and Barbas C, J. Pharm Biomed Anal., 2003, 31(3), 499-506. 


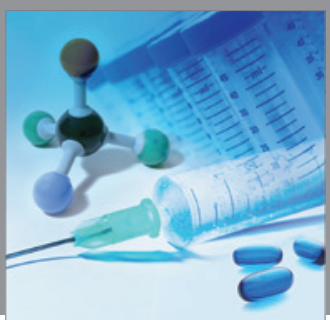

International Journal of

Medicinal Chemistry

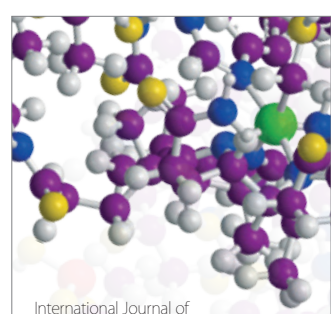

Carbohydrate Chemistry

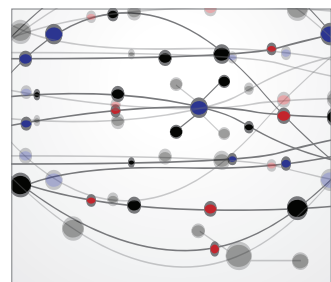

The Scientific World Journal
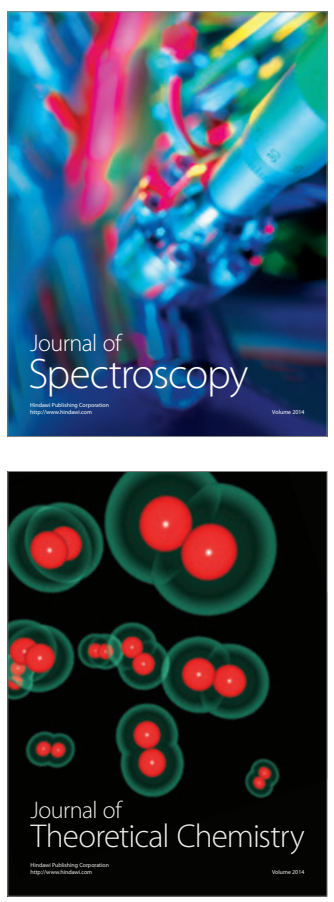
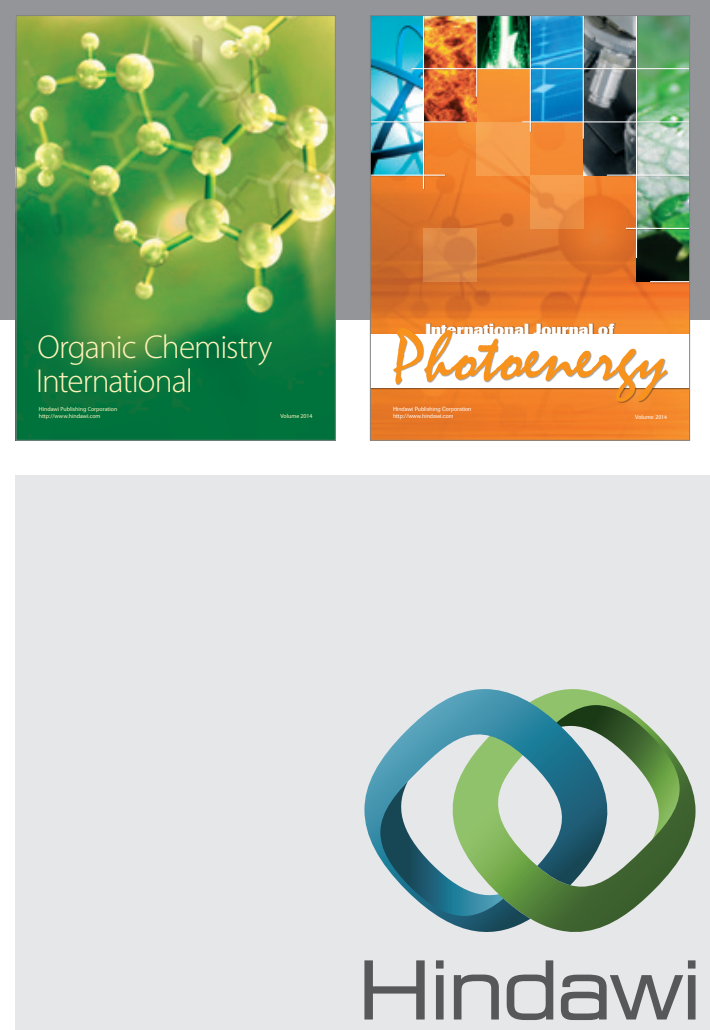

Submit your manuscripts at

http://www.hindawi.com
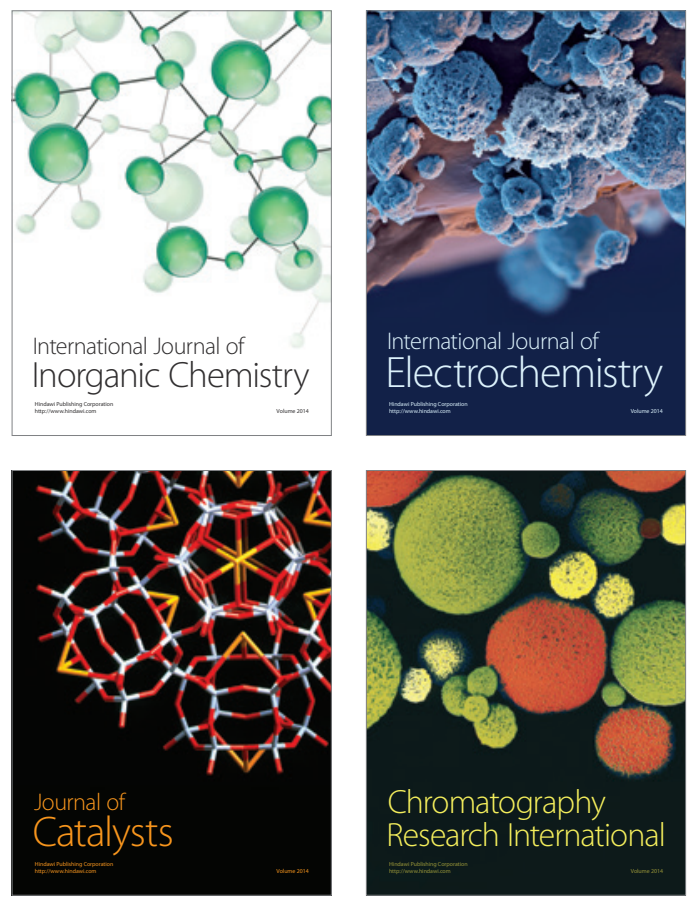
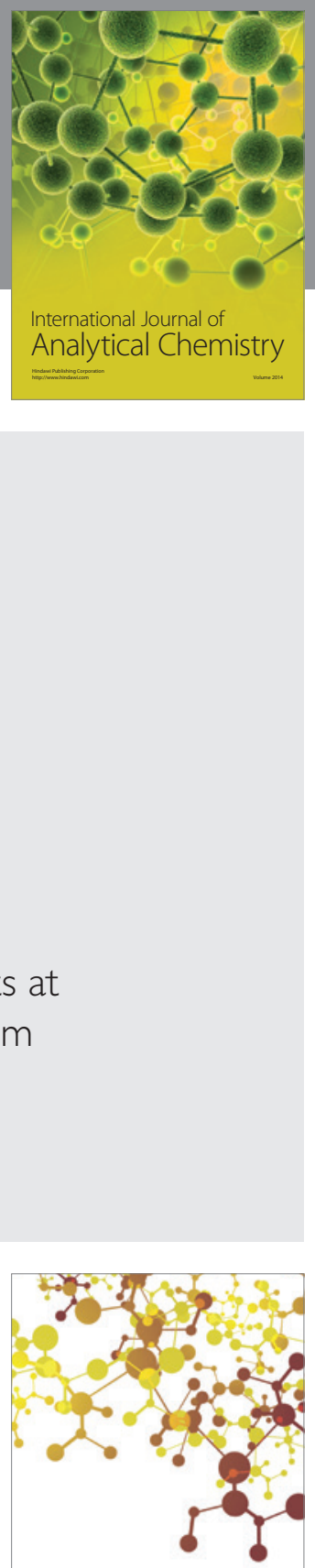

Journal of

Applied Chemistry
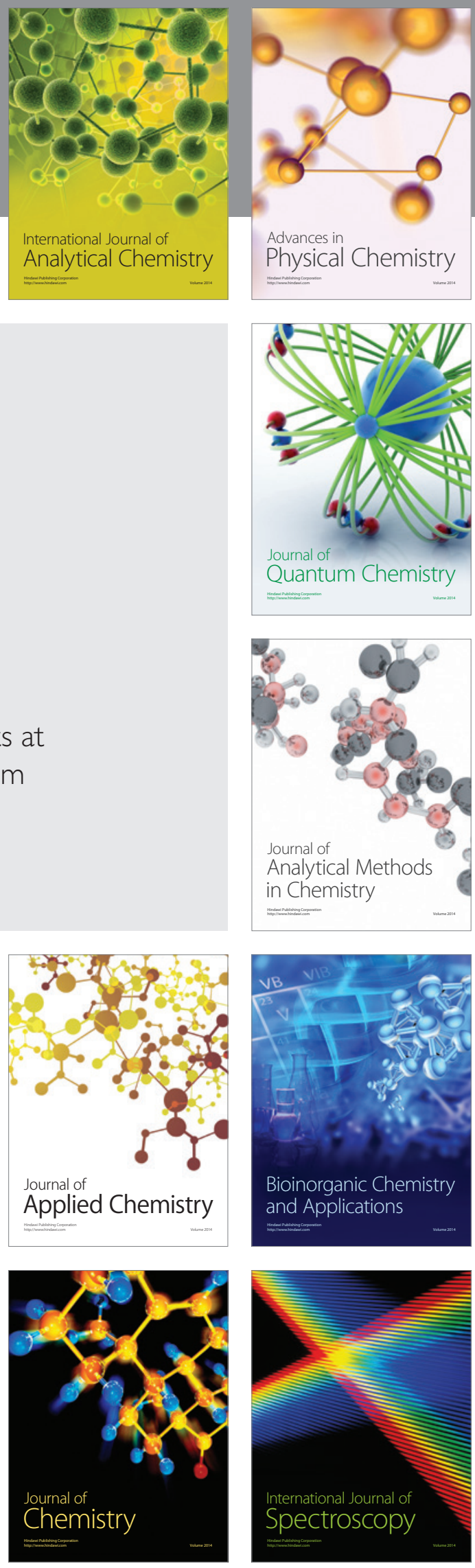